\title{
Investigation of minerals, testosterone, and transaminases in the semen and serum of fertile and infertile men belongs to different age groups
}

\author{
Zahed Mahmood ${ }^{1 *}$, Muhammad Riaz ${ }^{1}$, Imtiaz Mahmood Tahir ${ }^{1}$, Abdul Shakoor $^{1}$, Zia Ur Rahman $^{2}$, \\ Muhammad Usman Qamar Saeed ${ }^{1}$ \\ ${ }^{1}$ Department of Chemistry and Biochemistry, University of Agriculture, Faisalabad, Pakistan \\ ${ }^{2}$ Department of Physiology and Pharmacology, University of Agriculture, Faisalabad, Pakistan \\ Email: ${ }^{\text {drzahiduaf2003@yahoo.com }}$
}

Received 24 June 2012; revised 28 July 2012; accepted 10 August 2012

\begin{abstract}
The present study was aimed to assess the potential of infertility to induce the adverse effects with reference to testosterone, Triiodothyronine (T3), Thyroxine (T4), Alanine Aminotransferase (ALT), Aspartate Aminotransferase (AST), zinc, copper and iron. All the samples were divided into four groups according to age and disorder (Group 1, 10 infertile men of 25 - 40 years; Group 2, 10 fertile men of 25 - 40 years; Group 3, 10 infertile men of $41-60$ years and Group 4, 10 fertile men of 41 - 60 years). Semen and blood samples were analyzed by atomic absorption spectrophotometry to determine minerals while, Testosterone, $T 3$ and $\mathrm{T} 4$ were determined by enzyme immunoassay kits. ALT and AST were determined using standard kit assay method. The levels of testosterone and T3 and AST in the fertile semen of $41-60$ years age group were increased significantly $(P \leq 0.001)$ as compared to that of fertile semen of 25 - 40 years age group. While, the level of T4 in the fertile semen of 41 - 60 years age group was decreased significantly $(P \leq$ 0.001) as compared to that of fertile semen of $25-40$ years age group. In case of fertile serum, only the level of testosterone was significantly decreased $(P \leq$ 0.05 ) in the 41 - 60 years age group as compared to 25 - 40 years age group. The levels of testosterone and $\mathrm{Cu}$ in the infertile serum of $41-60$ years age group were decreased significantly $(\mathrm{P} \leq 0.001)$. While, the levels of T3, T4, ALT and Fe in the infertile serum of 41 - 60 years age group were increased significantly ( $P$ $\leq \mathbf{0 . 0 5}$ ) as compared to that of infertile serum of 25 40 years age group.
\end{abstract}

Keywords: Semen; Reproduction; Infertility; Minerals; Testosterone; Transaminases

"Corresponding author.

\section{INTRODUCTION}

Infertility primarily refers to the biological inability of a person to contribute to conception. According to World Health Organization [1], infertility is a period of two years without conception. After one year of infertility many couples seek a medical opinion because modern artificial reproduction techniques like intra-cytoplasmic sperm injection (ICSI) can help couples to overcome infertility [2]. Sub fertility is the failure to conceive after 1 year of regular, unprotected intercourse with the same partner. Sub fertility is caused by sperm defects or dysfunction [3].

Testosterone is a principal male sex hormone and is primarily secreted in the testes of males. In men, testosterone plays a crucial role in the development of male reproductive tissues such as the testis and prostate as well as promoting secondary sexual characteristics such as increased muscle, bone mass and the growth of body hair [4]. The thyroid hormones, T3, and T4 are tyrosine based hormones formed by the thyroid gland mainly responsible for regulation of metabolism [5]. ALT and AST are enzymes located in liver cells that leak out into the general circulation during the injury of liver cells [6].

Among the metal trace elements Zinc is one of the most interesting nutritional traces in the reproductive system. In man it is a cofactor of more than 200 metallo-enzymes and plays an important role in the normal testicular development, spermatogenesis, and sperm motility [7]. Copper is an essential trace element required in the diet because it is the metal cofactor for a variety of enzymes (amine oxidase, superoxide dismutase, cytochrome oxidase and tyrosinase). However, excess copper can cause problems because of its capacity to oxidize proteins and lipids, bind to nucleic acids and enhancing the production of free radicals. Therefore, it is important to maintain the amount of copper in the body within normal limits. Copper reduces sperm motility by reduc- 
ing oxidative processes and glucose consumption [8]. Iron is a vital component of a group of heme proteins that function in oxygen transport or as enzymes in redox systems. A small amount of iron is enclosed in several non heme metalloenzymes. The chief complexes coordinating iron with the cell are heme and heme containing proteins, hemosiderin and ferritin $[9,10]$. The aim of this study was to assess the potential causes of infertility and old age to induce the adverse effects with reference to testosterone, T3, T4, ALT, AST, zinc, copper and iron.

\section{MATERIALS AND METHODS}

\subsection{Sample Collection}

Semen and blood samples were collected from each individual patient of each group. Semen samples were collected by masturbation in a clean specimen container after sexual abstinence for 3 - 5 days followed by liquefaction at $37^{\circ} \mathrm{C}$. The semen samples were evaluated according to World Health Organization recommendations (ejaculate volume, $\mathrm{pH}$, time to liquefaction, sperm concentration, motility and morphology). The remaining semen samples were centrifuged at $3000 \times \mathrm{g}$ for $10 \mathrm{~min}$ to obtain the seminal plasma. The separated seminal plasma was stored at $-80^{\circ} \mathrm{C}$ until further analysis for the detection of testosterone, $\mathrm{Zn}, \mathrm{Cu}, \mathrm{Fe}, \mathrm{T} 3, \mathrm{~T} 4, \mathrm{ALT}$ and AST level. Blood samples were centrifuged at $4000 \times \mathrm{g}$ for 15 min after complete coagulation and supernatant serum was collected in Eppendorf tubes and frozen until further analysis for the detection of testosterone, $\mathrm{Zn}, \mathrm{Cu}, \mathrm{Fe}, \mathrm{T}$, T4, ALT and AST level.

\subsection{Measurement of Minerals}

Zinc, iron and copper in the samples were measured by atomic absorption spectrophotometer. The samples were aspirated to the instrument and reading was recorded at the Monochromator wavelength 213.9, 285.2 and 342.7 $\mathrm{nm}$ for zinc, iron and copper respectively.

\subsection{Measurement of Testosterone}

Testosterone was determined with the help of DRG Testosterone Enzyme Immunoassay Kit.

\subsection{Measurement of $\mathrm{T} 3 \& \mathrm{~T} 4$}

Triiodothyronine (T3) and Thyroxine (T4) were determined by using J D Biotech T3 and J D Biotech T4 Enzyme Immunoassay Kit respectively.

\subsection{Measurement of ALT}

Human Gasellschaft fur Biochemica and diagnostica $\mathrm{mbH}$ (EC 3.1.3.1) kit was used to determine the level of ALT as described by Saher et al. [11].

\subsection{Measurement of AST}

The AST was evaluated by adopting the methodology as described by Reitman and Frankel [12].

\subsection{Statistical Analysis}

The results were expressed as mean \pm SEM for all continuous variables. Mean \pm SEM have been prepared in Microsoft ${ }^{\circledR}$ Excel Windows Version 2007. The data obtained were analyzed by applying student t-test using Minitab 15 Windows Version to assess the significant differences between all selected age groups.

\section{RESULTS AND DISCUSSION}

The levels of testosterone and T3 and AST in the fertile semen of $41-60$ years age group were increased significantly $(\mathrm{P} \leq 0.001)$ as compared to that of fertile semen of 25 - 40 years age group. While, the level of T4 in the fertile semen of $41-60$ years age group was decreased significantly $(\mathrm{P} \leq 0.001)$ as compared to that of fertile semen of 25 - 40 years age group. There was no significant difference among the levels of ALT, $\mathrm{Zn}, \mathrm{Cu}$ and Fe between the fertile semen of $25-40$ years age group and 41 - 60 years age group (Figure 1).

In case of fertile serum, only the level of testosterone was significantly decreased $(\mathrm{P} \leq 0.05)$ in the $41-60$ years age group as compared to $25-40$ years age group. While, the levels of T3, T4, ALT, AST, Zn, Cu and Fe had no significant difference between the fertile serums of 25 - 40 years age group and $41-60$ years age group (Figure 2).

In the infertile semen of $41-60$ years age group, the levels of testosterone, $\mathrm{T} 4, \mathrm{Zn}$ and $\mathrm{Cu}$ were decreased significantly $(\mathrm{P} \leq 0.001, \mathrm{P} \leq 0.05)$ as compared to that of infertile semen of $25-40$ years age group. While, the levels of T3, ALT and AST were increased significantly $(\mathrm{P} \leq 0.001, \mathrm{P} \leq 0.05)$ in the infertile semen of $41-60$ years age group as compared to that of infertile semen of 25 - 40 years age group (Figure 3 ).

The levels of testosterone and $\mathrm{Cu}$ in the infertile serum of 41 - 60 years age group were decreased significantly ( $\mathrm{P}$ $\leq 0.001)$ as compared to that of fertile semen of $25-40$ years age group. While, the levels of T3, T4, ALT and Fe in the infertile serum of $41-60$ years age group were increased significantly $(\mathrm{P} \leq 0.001, \mathrm{P} \leq 0.05)$ as compared to that of infertile serum of 25 - 40 years age group (Figure 4).

\section{DISCUSSION}

The lower level of testosterone in the fertile serum of 41 - 60 years age group as compared to that of fertile serum of 25 - 40 years age group indicates that testosterone level is decreased in older age resulting in the decreased 


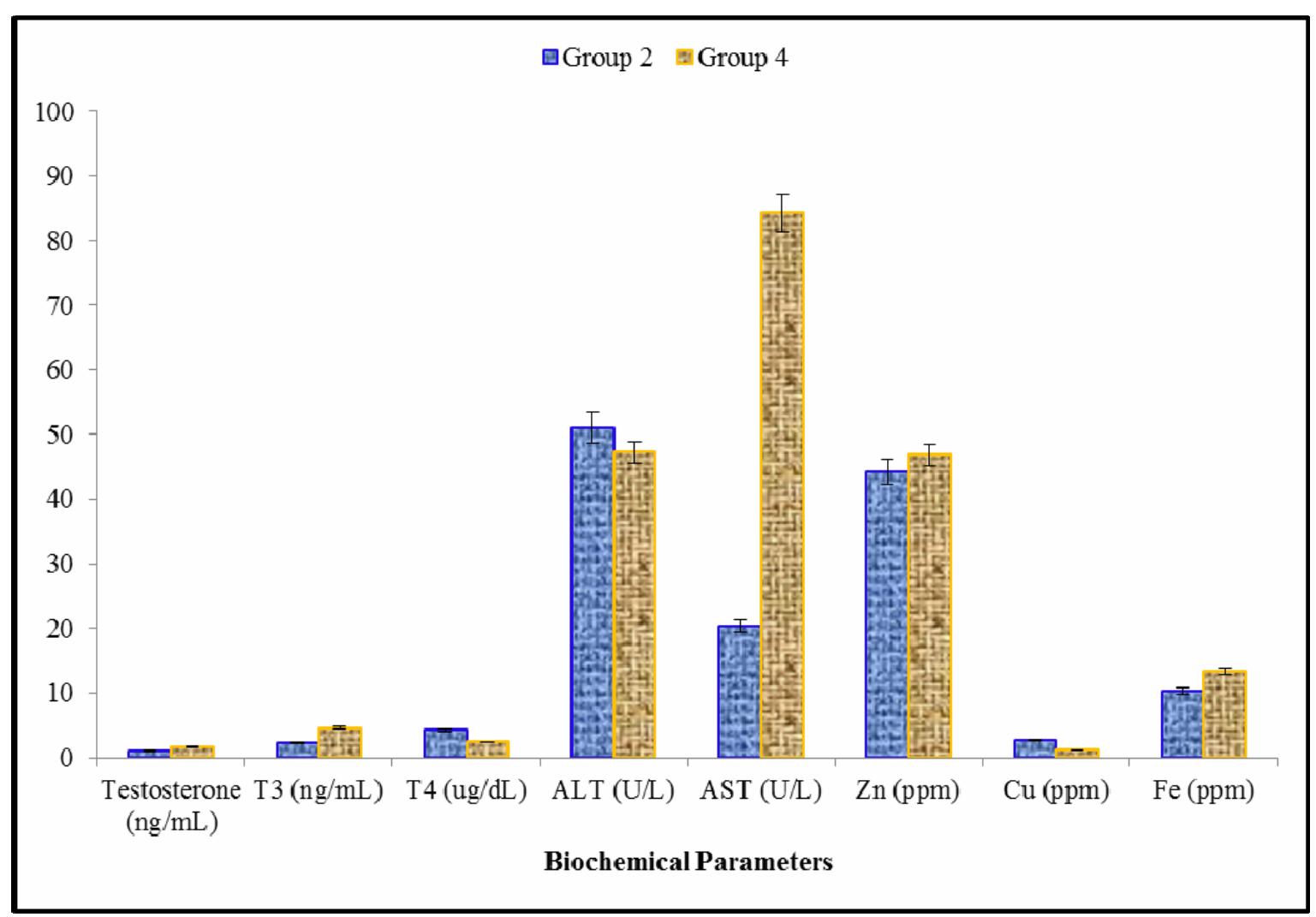

Figure 1. Biochemical parameters evaluation in fertile semen of age group $2 \& 4$.

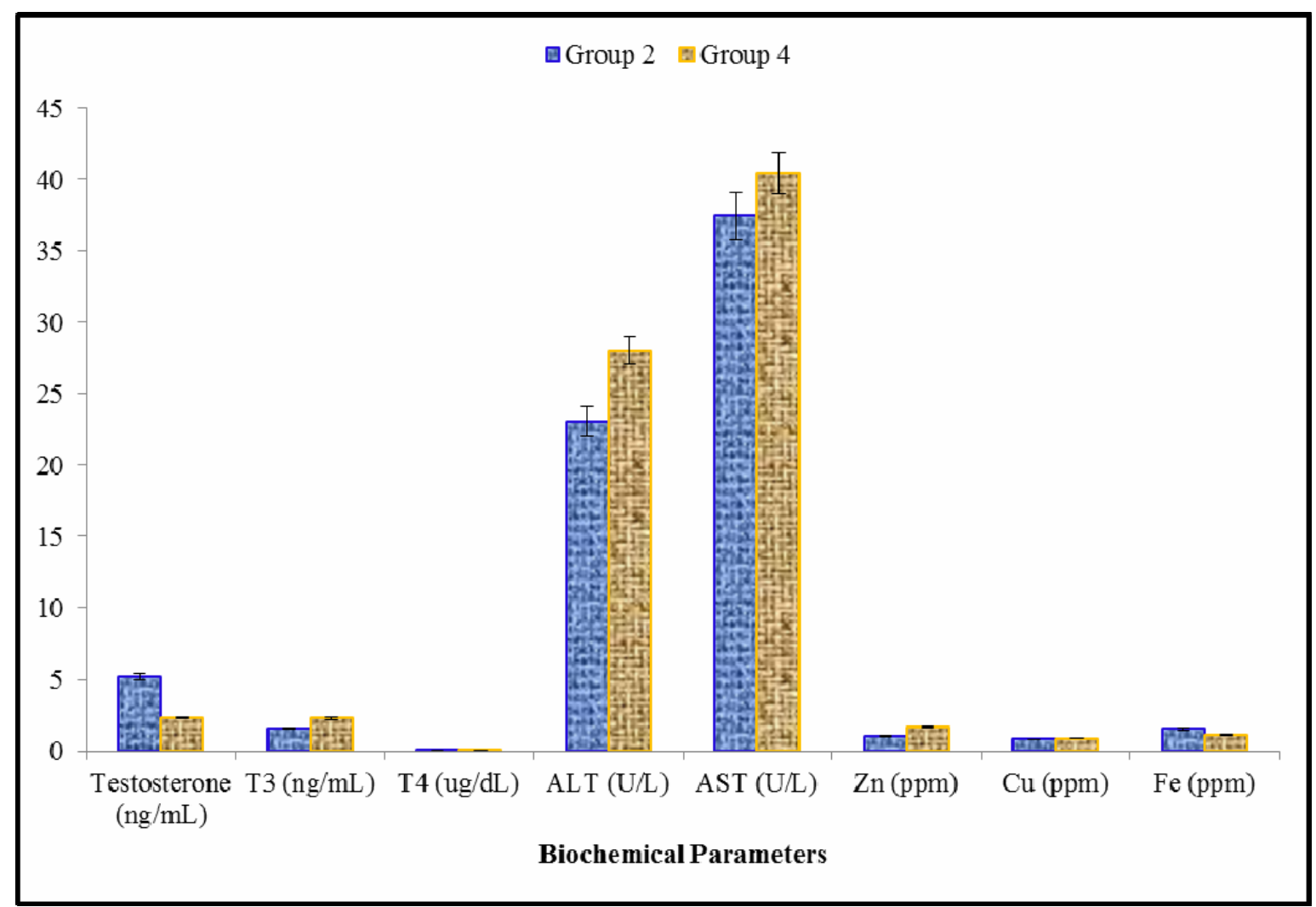

Figure 2. Biochemical parameters evaluation in fertile serum of age group $2 \& 4$. 


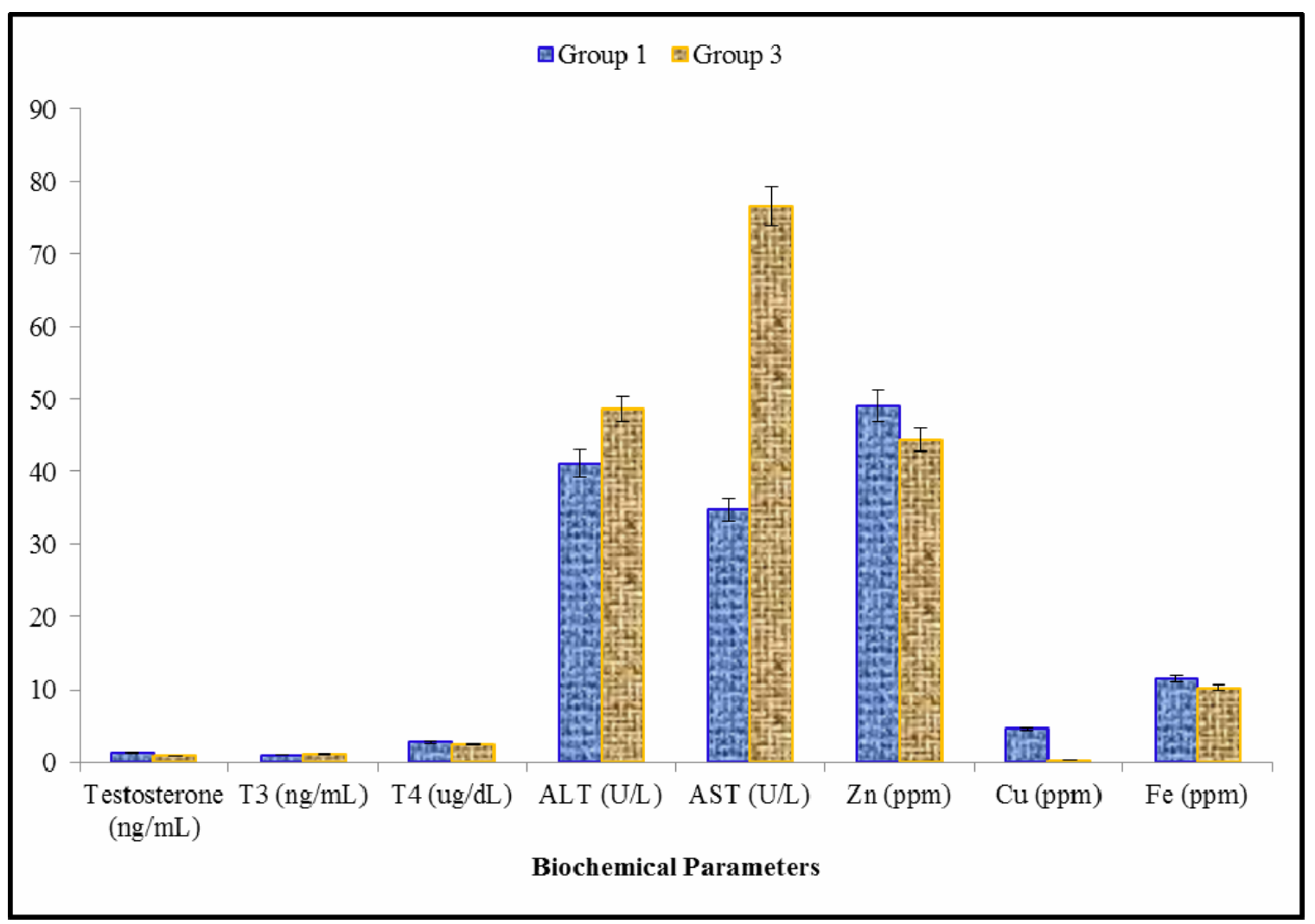

Figure 3. Biochemical parameters evaluation in the infertile semen of age group $1 \& 3$.

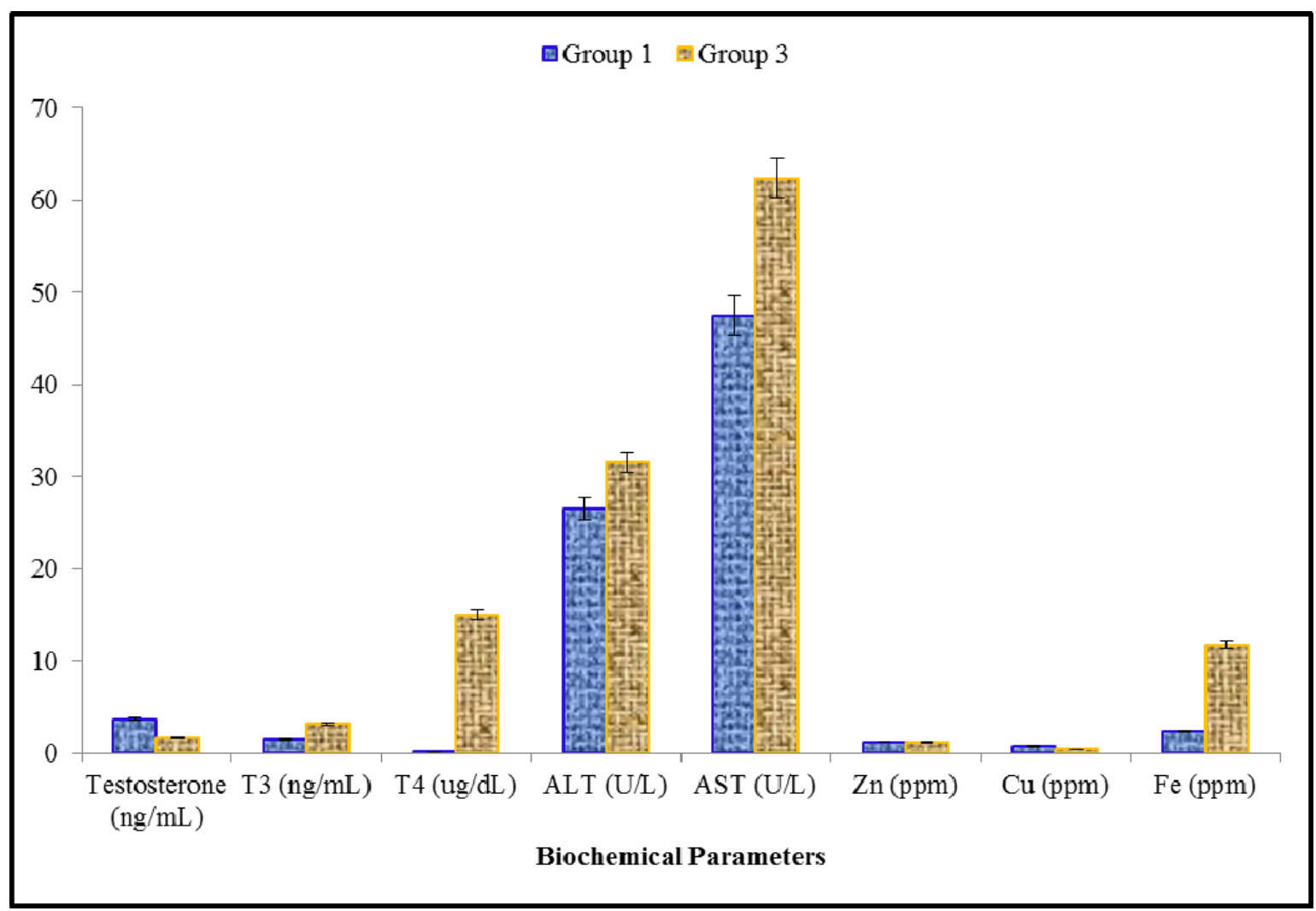

Figure 4. Biochemical parameters evaluation in the infertile serum of age group $1 \& 3$. 
sperm production. In consequence, the testosterone concentration is increased in the fertile semen of $41-60$ years age group as compared to that of fertile semen of 25 - 40 years age group to increase the sperm production. Significantly lower level of testosterone in the infertile serum of $41-60$ years age group represents that testosterone deficiency is more pronounced in older age. This may be due to atrophy of glandular tissue of pituitary or testes resulting in significantly lower level of testosterone in the infertile semen of $41-60$ years age group. This may also be due to prostatic inflammation and obstruction or blockage of the male reproductive tract. Hence testis not functioning properly and testosterone production is affected. Zinc deficiency in infertile semen of 41 - 60 years age group also causes lower testosterone production as zinc is involved in steroidogenesis, testicular development and testosterone synthesis [3]. The similar results were found by Khan et al. [13]. They observed the decrease in testosterone concentration in the infertile individuals. Omrani et al. [14] and Weedin et al. [15] also found the decreased testosterone level in the infertile men.

Significantly lower level of zinc in the infertile semen of 41 - 60 years age group in the present study might be due to excessive ROS production. After ejaculation the abnormal spermatozoa are sources of oxidants which bind with the zinc and reduce its concentration in seminal plasma. Hence, zinc is considered to be an important antioxidant protecting the spermatozoa from oxidative stress. Zinc deficiency decreases testicular weight and causes shrinkage of the seminiferous tubules. Zinc deficiency also induces atrophy of the seminiferous tubules and causes failure of the spermatogenesis. Low seminal zinc levels have been correlated with decreased fertility potential [16]. Ali et al. [17] observed the low zinc level in the infertile subjects and found that low zinc level affected the semen parameters. Colagar et al. [18] found that poor $\mathrm{Zn}$ nutrition may be an important risk factor for low quality of sperm and idiopathic male infertility.

Significantly lower level of Copper in the infertile semen and serum of $41-60$ years age group may be due to liver toxicity as it is absorbed by the liver, bound to albumin and excreted into the bile. It is also involved in protein synthesis during certain enzymatic reactions acting as a cofactor. Nutritional deficiency may also lower its level in infertile men. Abdul-Rasheed [19] reported a significant decrease in seminal plasma copper levels in azoospermic patients. In the present research work, significant increase of iron in the infertile serum might be due to oxidative stress in infertile men. Aydemir et al. [20] observed the increased iron level in the infertile men. Eghbali et al. [10] reported that seminal plasma iron content is related with the motility and viability of the spermatozoa after ejaculation. Presence of iron in the seminal plasma will assist spermatozoa to sustain their functions as long as it is needed for semen fertility.

\section{ACKNOWLEDGEMENTS}

The authors express gratitude to the lab staff of Physiology and Pharmacology Department, Faculty of Veterinary Sciences and Staff of Biomedical Lab, University of Agriculture Faisalabad, Pakistan. On providing lab facilities authors are also grateful to the Mian Muhammad trust Hospital Faisalabad and Biocare Labs, Aziz Fatima Hospital Faisalabad, Pakistan.

\section{REFERENCES}

[1] World Health Organization (2003) Laboratory manual for the examination of human semen and semen-Cervical mucus interaction. 4th Edition, Cambridge University Press, Cambridge, 60.

[2] Poongothai, J., Gopenath, T.S. and Manonayaki, S. (2009) Genetics of human male infertility. Singapore Medical Journal, 50, 336-347.

[3] Ebisch, I.M.W., Thomas, C.M.G., Peters, W.H.M., Braat, D.D.M. and Steegers-Theunissen, R.P.M. (2007) The importance of folate, zinc and antioxidants in the pathogenesis and prevention of subfertility. Human Reproduction Update, 13, 163-174. doi:10.1093/humupd/dml054

[4] Reed, W.L., Clark, M.E., Parker, P.G., Raouf, S.A., Arguedas, N., Monk, D.S., Snajdr, E., Nolan, V. and Ketterson, E.D. (2006) Physiological effects on demography: A longterm experimental study of testosterone's effects on fitness. The American Naturalist, 167, 667-683. doi:10.1086/503054

[5] Al-Juboori, I.A., Al-Rawi, R. and A-Hakeim, H.K. (2009) Estimation of serum copper, manganese, selenium, and zinc in hypothyroidism patients. IUFS Journal of Biology, 68, 121-126.

[6] Tolman, K.G. and Rej, R. (1999) Liver function. In: Burtis, C.A. and Ashwood, E.R., Eds., Tietz Textbook of Clinical Chemistry, 3rd Edition, Saunders, Philadelphia, 11581159.

[7] Promdee, L. and Pongsritasana, T. (2005) Zinc level in seminal plasma of infertile men. Srinagarind Medical Journal, 20, 38-42.

[8] Roychoudhury, S., Slivková, J., Bulla, J. and Massányi, P. (2008) Copper administration alters fine parameters of spermatozoa motility in vitro. Folia Veterinaria, 52, 6468.

[9] Sarafanov, A.G., Todorov, T.I. and Kajdacsy-Balla, A. (2008) Analysis of iron, selenium and cadmium in paraffinembedded prostate tissue specimens using inductively coupled plasma massspectrometry. Journal of Trace Elements of Medicine and Biology, 22, 305-314. doi:10.1016/j.jtemb.2008.03.010

[10] Eghbali, M., Alavi-Shoushtari, S.M., Asri-Rezaei, S. and Ansari, M.H.K. (2010) Effects of the seminal plasma iron and lead content on semen quality of water buffalo (Bubalus bubalis) bulls. Veterinary Research Forum, 3, 142-148.

[11] Saher, F., Rehman, K., Qureeshi, J.A., Irshad, M. and 
Iqbal, H.M.N. (2012) Investigation of an inflammatory viral disease $\mathrm{HBV}$ in cardiac patients through polymerase chain reaction. Advances in Bioscience and Biotechnology, in press.

[12] Reitman, S. and Frankel, S. (1957) A colorimetric method for the determination of serum glutamic oxaloacetic and glutamic pyruvic transaminases. American Journal of Clinical Pathology, 28, 56-63.

[13] Khan, M.S., Ali, I., Hassan, M., Nawaz, K., Zeb, M., Anwar, W., Zada, A.U.L. and Javed, A. (2007) Determination of serum gonadotropin and testosterone levels in male infertility. Journal of Postgraduate Medical Institute, 21, 86-91.

[14] Omrani, M.D., Samadzadae, S., Bagheri, M. and Attar, K. (2006) Y chromosome microdeletions in idiopathic infertile men from west Azarbaijan. Journal of Urology, 3, 3843.

[15] Weedin, J.W., Bennett, R.C., Fenig, D.M., Lamb, D.J. and Lipshultz, L.I. (2011) Early versus late maturation arrest: Reproductive outcomes of testicular failure. Journal of Urology, 186, 621-626.

doi:10.1016/j.juro.2011.03.156
[16] Marmar, J.L., Katz, S., Praiss, D.E. and DeBenedictis, T.J. (1975) Semen zinc levels in infertile and postvasectomy patients and patients with prostatitis. Fertility and Sterility, 26, 1057-1063.

[17] Ali, H., Ahmed, M., Baig, M. and Ali, M. (2007) Relationship of zinc concentrations in blood and seminal plasma with various semen parameters in infertile subjects. Pakistan Journal of Medical Sciences, 23, 111-114.

[18] Colagar, A.H., Marzony, E.T. and Chaichi, M.J. (2009) Zinc levels in seminal plasma are associated with sperm quality in fertile and infertile men. Nutrition Research, 29, 82-88. doi:10.1016/j.nutres.2008.11.007

[19] Abdul-Rasheed, O.F. (2010) Association between seminal plasma copper and magnesium levels with oxidative stress in Iraqi infertile men. Oil Market Journal, 25, 168172.

[20] Aydemir, B., Kiziler, A.R., Onaran, I., Alici, B., Ozkara, H. and Akyolcu, M.C. (2006) Impact of $\mathrm{Cu}$ and Fe concentration on oxidative damage in male infertility. Biological Trace Element Research, 112, 193-203. doi:10.1385/BTER:112:3:193 